International Journal of Advanced Chemistry, 9(2)(2021) $65-69$
International Journal of Advanced Chemistry
SPC
Website: www.sciencepubco.com/index.php/IJET
Research paper

\title{
Analysis of Inhibition Action of Acacia nilotica Ethanol Extract on Aluminium Corrosion in 1.0M HCl and $\mathrm{NaOH}$
}

\author{
Abdul S. U. 1 *, Ibrahim M. B. ${ }^{1}$, Ibrahim M. A. ${ }^{1}$ \\ ${ }^{1}$ Department of Pure and Industrial Chemistry, Bayero University, Kano \\ *Corresponding author E-mail: sanidanmaraya@gmail.com
}

\begin{abstract}
The proposed corrosion inhibition action of Acacia nilotica ethanol extract on aluminium corrosion in $\mathrm{HCl}$ and $\mathrm{NaOH}$ was investigated using weight loss method. The Acacia nilotica ethanol extract was found to be inactive in $\mathrm{NaOH}$ at all the concentrations of the inhibitor but active in $\mathrm{HCl}$ with increasing inhibition efficiency as inhibitor concentration and decreases as temperature increases with the highest inhibition efficiency of $95.31 \%$. The kinetic and thermodynamics data shows that the adsorption process was feasible and endothermic adsorption process from the large negative values of Gibb's free energy $(\Delta \mathrm{G})$ and negative values of enthalpy $(\Delta \mathrm{H})$, The data indicated physisorption process of adsorption which was supported by FTIR spectra. The adsorption process was best fitted to Langmuir adsorption model.
\end{abstract}

Keywords: Acacia nilotica; Adsorption; Corrosion Inhibition; Kinetic; Thermodynamics.

\section{Introduction}

The term metal corrosion is defined as the interaction of a metal with the surrounding envirounment, causing a slow, steady and irreversible deterioration of metal, in both physical and chemical properties (Rafael et al, 2014). It is the destruction of materials resulting from exposure and interaction with the corrosive envirounment. It is a major problem that must be confronted for safety, envirounment and economic reasons (Thomson et al, 2007). The basic processes of metallic corrosion in aqueous media consist of the anodic dissolution of the metals and cathodic reduction of oxidants present in the solution (Sharma, 2012).

The generic formula for anodic metal loss can be represented by the equation below:

$\mathrm{M} \rightarrow \mathrm{M}^{+}+\mathrm{e}^{-}$Oxidation

The produced electrons are consumed at the cathodic site, with two possibilities in solution:

$2 \mathrm{H}_{(\mathrm{aq})}^{+}+2 \mathrm{e}^{-} \rightarrow \mathrm{H}_{2(\mathrm{~g})}$ Reduction

$\mathrm{O}_{2(\mathrm{~g})}+\mathrm{H}_{2} \mathrm{O}_{(\mathrm{l})}+4 \mathrm{e}^{-} \rightarrow 4 \mathrm{OH}^{-}$Reduction

Aluminium is widely used for many industrial and domestic purposes. It is used in the field of aerospace, transportation, electronics, electricity, construction and in manufacturing chemical reactors, medical equipments, petroleum refining units, oil and gas pipelines, kitchen wears etc. The advantage of using aluminum is due to its excellent corrosion resistance properties and thus it becomes a priority in material selections in most industries (Hajar et.al, 2016).

Although aluminium has an adhesive protective passive oxide film, but this film has an atmospheric susceptibility and consequently the metal dissolves readily in acidic and basic solutions above and below the range of pH 4-9 (Aytac, 2010; Obot et,al, 2008).

Corrosion inhibitors are either organic or inorganic chemicals or more commonly formulations that are added in small amount to a corrosive envirounment in order to delay or decrease the corrosion process of the surface to be protected (Palou et al, 2014). The applications of corrosion inhibitor have been an accepted practice (Khan et al, 2015). Many of these inhibitor are toxic and do not conform with requirements of the environmental protection standards. As the alternative of toxic corrosion inhibitors and environmental friendly, plant extracts are receiving more attentions as better corrosion inhibitor (El-etre, 2007; Okafor et al, 2008). With regard to these findings, the current research investigated the corrosion inhibitive activity of Acacia nilotica fruits ethanol extract on the corrosion of aluminium in acidic and alkaline media. 


\section{Materials and Methods}

Preparation of coupons: The metal was mechanically pressed cut into $2 \times 2 \mathrm{~cm}$ with a very small hole close to the edge of the coupons, were degreased in acetone and kept in a dessicator.

Preparation of inhibitor: The fresh fruits of Acacia nilotica were obtained from a farm in Lengel, Kano, Nigeria. The fruits were washed, air dried, ground into powder. $100 \mathrm{~g}$ of the fruit powder was weighed into $1.0 \mathrm{dm}^{3}$ of absolute ethanol contained in an ambered bottle. It was left to stand for seven days with occasional shaking. The mixture was filtered and the filtered was concentrated using rotary evaporator and thick syrup was obtained which was dried further for total solvent removal (Mahalakhshimi, 2016).

Weight loss method: The weight aluminum coupons were separately immersed in the $100 \mathrm{~cm}^{3}$ opened beakers containing the test solution of a given concentration with and without a given concentration of the inhibitor at a particular temperature maintained in a thermostated water bath. At the given interval of time the coupons were retrieved from the test solution, washed with brush under running water, dried in acetone and weighed again. This was done in replicate. The weight loss $(\Delta \mathrm{w})$, corrosion rate (CR), surface coverage $(\theta)$ and inhibition efficiency were determined using the equation (1), (2), (3) and (4) respectively.

$$
\begin{aligned}
& \Delta \mathrm{w}=\mathrm{w}_{\mathrm{i}}-\mathrm{w}_{\mathrm{f}} \\
& \mathrm{CR}=\frac{\Delta \mathrm{w}}{\mathrm{At}} \\
& \theta=\frac{\mathrm{w}_{\mathrm{o}}-\mathrm{w}_{1}}{\mathrm{w}_{\mathrm{o}}} \\
& \% \mathrm{IE}=\frac{\mathrm{w}_{\mathrm{o}}-\mathrm{w}_{1}}{\mathrm{w}_{\mathrm{o}}} \times 100
\end{aligned}
$$

FTIR analysis: The Fourier transform spectrophotometer (Cary 630) from Agilent technology was used for the determination of the functional group present in the extract and in the corrosion products on the metal surface in presence of the extract.

\section{Result and discussion}

Effect of Immersion Time: Weight loss for the corrosion of aluminium in $0.2 \mathrm{M} \mathrm{HCl}$ and $\mathrm{NaOH}$ solutions at $298 \mathrm{~K}$ for different immersion period in the absence of inhibitor were determined and the results were presented in figures 1 and 2 . From figures 1 and 2 , there was no weight loss observed in $\mathrm{HCl}$ for the time interval of 0.083 to 0.750 hours while weight loss for aluminium in $\mathrm{NaOH}$ was 0.0006 and $0.0216 \mathrm{~g}$ at the same experimental conditions and the maximum immersion time possible was 5 hours for aluminium in $\mathrm{NaOH}$ and 24 hours in $\mathrm{HCl}$. Generally weight loss was found to increase with the increase in immersion time. Similar results were reported in literature (Nwaedozie et al, 2015).

(A)

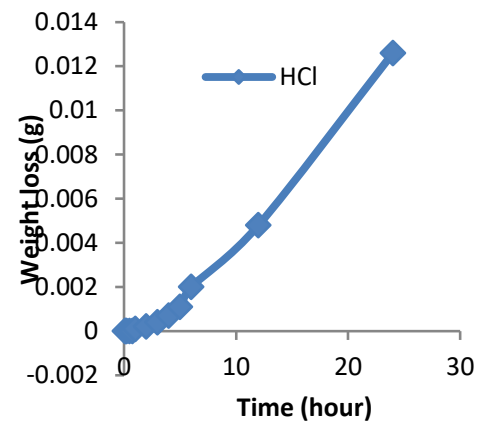

(B)

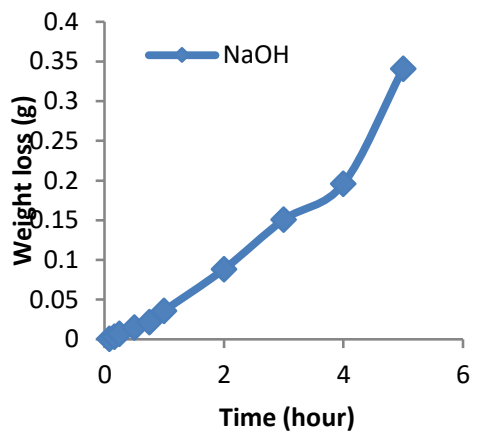

Fig. 1: Variation of Weight Loss with Immersion Time for Aluminium in $0.2 \mathrm{M} \mathrm{HCl}(\mathrm{A})$ and $\mathrm{NaOH}(\mathrm{B})$.

Effect of temperature: The variations of weight loss, corrosion rate, sureface coverage, inhibition efficiency as a function of temperature with and without $0.1 \% \mathrm{w} / \mathrm{v}$ are presented in table 1 and 2 respectively. At all tested temperature, the inhibitor was found to retard the weight loss and corrosion rate only in $\mathrm{HCl}$ and it was not active in $\mathrm{NaOH}$. Weight loss and corrosion rate increases with temperature thereby decreasing surface coverage and inhibition efficiency. Result similar to this was reported in literature (Maibalangu et al, 2017). The increase in corrosion rate as temperature increases can be explained on the basis of desorption as a result of unstable nature of active phytochemicals when temperature is increased (Bouhlal et al, 2020).

Table 1: Variation of Weight Loss and Corrosion Rate with Temperature in $\mathrm{HCl}$ and $\mathrm{NaOH}$ without Inhibitor

\begin{tabular}{lllll}
\hline Temperature $(\mathrm{K})$ & $\begin{array}{l}\mathrm{HCl} \\
\text { Weight loss }(\mathrm{g})\end{array}$ & $\begin{array}{l}\text { Corrosion rate } \\
\left(\mathrm{gh}^{-1} \mathrm{~cm}^{-2}\right)\end{array}$ & $\begin{array}{l}\text { NaOH } \\
\text { Weight loss }(\mathrm{g})\end{array}$ & Corrosion rate $\left(\mathrm{gh}^{-1} \mathrm{~cm}^{-2}\right)$ \\
\hline 298 & 0.2151 & 0.0538 & 0.1207 & 0.0302 \\
303 & 0.2406 & 0.0602 & 0.1661 & 0.0415 \\
308 & 0.2860 & 0.0715 & 0.2292 & 0.0573 \\
313 & 0.3306 & 0.0827 & 0.3029 & 0.0757 \\
318 & 0.3622 & 0.0906 & 0.3801 & 0.0950 \\
\hline
\end{tabular}


Table 2: Variation of Weight Loss, Corrosion Rate, Surface Coverage $(\Theta)$ and Inhibition Efficiency (\%IE) with Temperature in HCl with $0.1 \%$ Inhibitor

\begin{tabular}{llll}
\hline Temperature $(\mathrm{K})$ & Weight loss $(\mathrm{g})$ & Corrosion rate $\left(\mathrm{gh}^{-1} \mathrm{~cm}^{-2}\right)$ & 0 \\
\hline 298 & 0.0138 & 0.0035 & 0.9358 \\
303 & 0.0383 & 0.0096 & 0.8407 \\
308 & 0.0476 & 0.0119 & 0.8337 \\
313 & 0.0694 & 0.0174 & 84.07 \\
318 & 0.0836 & 0.0209 & 83.37 \\
\hline
\end{tabular}

Effect of inhibitor concentration: The effect of inhibitor concentration on weight loss, corrosion rate, surface coverage and inhibition efficiency was investigated at $298 \mathrm{~K}$ and the results were presented in table 3 . The Acacia nilotica extract was found to be inactive in $\mathrm{NaOH}$ but weight loss was and corrosion rate were found to decrease with the increase in the concentration of the inhibitor in $\mathrm{HCl}$, hence, increase in surface coverage and inhibition efficiency. A similar trend was reported by other authors (Ituen et al, 2013; Maibalangu et al, 2017; Ibrahim et al, 2019). The increase in inhibition efficiency with increasing the concentration of the inhibitor is due to the increase of the adsorbed amount and the coverage of the inhibitor molecules. (Fouda et al, 2013).

Table 3: Variation of Weight Loss, Corrosion Rate, Surface Coverage $(\Theta)$ and Inhibition Efficiency (\%IE) with Inhibitor Concentration in Hcl with At

\begin{tabular}{lllll}
$318 \mathrm{~K}$ & & & \\
\hline Inhibitor Conc. (\%) & Weight loss $(\mathrm{g})$ & Corrosion rate $\left(\mathrm{gh}^{-1} \mathrm{~cm}^{-2}\right)$ & $\Theta$ & $\%$ IE \\
\hline 0.1 & 0.0836 & 0.0209 & 0.7691 & 76.91 \\
0.2 & 0.0652 & 0.0163 & 0.8199 & 81.99 \\
0.3 & 0.0423 & 0.0106 & 0.8831 & 88.31 \\
0.4 & 0.0231 & 0.0058 & 0.9361 & 93.61 \\
0.5 & 0.0170 & 0.0043 & 0.9531 & 95.31 \\
\hline
\end{tabular}

Adsorption Isotherm: The data obtained from the degree of surface coverage were used to test different adsorption isotherms. The adsorption of Acacia nilotica on aluminium surface was fitted to Langmuir adsorption model (equation 5).

$\log \left(\frac{\mathrm{c}}{\theta}\right)=\log \mathrm{c}-\log \mathrm{k}$

Where $\mathrm{c}$ is the inhibitor concentration, $\theta$ is the surface coverage and $\mathrm{k}$ is the adsorption equilibrium constant. The plot of log $\left(\frac{\mathrm{c}}{\theta}\right)$ versus $\log \mathrm{c}$ was found to be linear and presented in figure 2 .

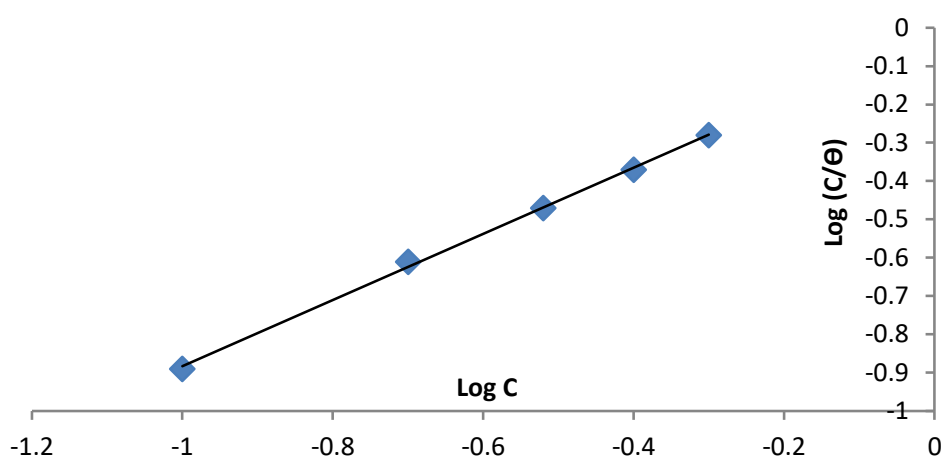

Fig. 2: Langmuir Adsorption Model Plot.

Thermodynamics and Kinetics: Arrhenius plot of $\log \mathrm{CR}$ against $1 / \mathrm{T}$ were plotted from Arrhenius equation (equation 6).

$\log C R=\log A-\frac{E_{a}}{2.303 R T}$

Where $\mathrm{CR}$ is the corrosion rate, $\mathrm{E}_{\mathrm{a}}$ is the activation energy, $\mathrm{R}$ is the molar gas constant and $\mathrm{T}$ is the temperature. The variation of $\mathrm{CR}$ with $1 / T$ is shown in figure 3 with the slope $=\frac{E_{a}}{2.303 R}$ and intercept $=A$. The calculated $E_{a}$ are presented in table 4 . The activation energy increases from that of the blank to the inhibited. The result suggest that the adsorption of Acacia nilotica on the aluminium involves physisorption as the activation energy is lower than the threshold value of $80 \mathrm{KJmol}^{-1}$ required for chemisorptions (Hamdy and EL-Gendy, 2012). 


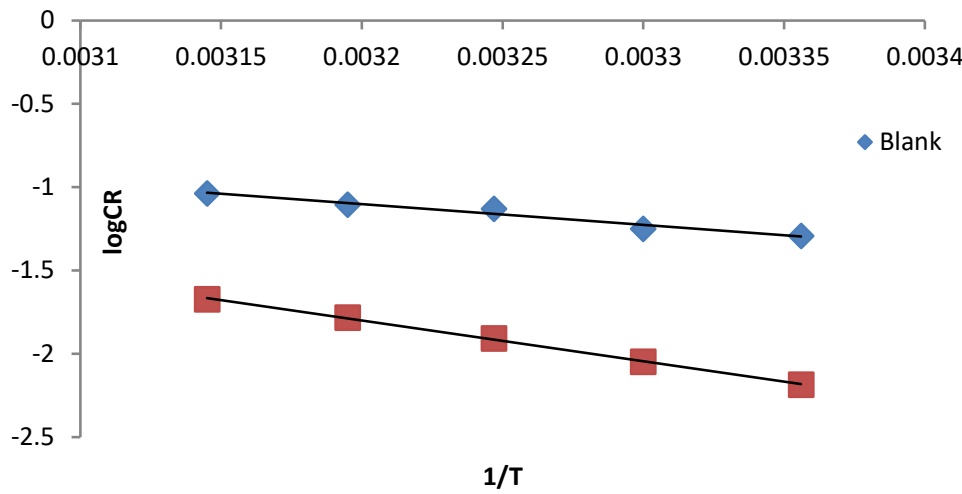

Fig. 3: Arrhenius Plot.

Erying transition state equation (equation 7) was considered for the determination of enthalpy $(\Delta \mathrm{H})$ and entropy $(\Delta \mathrm{S})$.

$\log \frac{\mathrm{CR}}{\mathrm{T}}=\log \frac{\mathrm{R}}{\mathrm{Nh}}+\frac{\Delta \mathrm{S}}{2.303 \mathrm{R}}-\frac{\Delta \mathrm{H}}{2.303 \mathrm{RT}}$

Where $\mathrm{N}$ is the Avogadro's constant and $\mathrm{h}$ is the Plank constant. The plot of $\frac{\mathrm{CR}}{\mathrm{T}}$ against 1/T (figure 13) gives a straight line graph with the slope $=\frac{\Delta \mathrm{H}}{2.303 \mathrm{R}}$ and intercept $=\left(\frac{\mathrm{R}}{\mathrm{Nh}}\right)+\left(\frac{\Delta \mathrm{S}}{2.303 \mathrm{R}}\right)$. The calculated values of enthalpy and entropy were presented in table 4 . The findings suggest that the endothermic nature of the process from the positive values of $\Delta \mathrm{H}$. The absolute values of $\Delta \mathrm{H}$ is $49.99 \mathrm{kJmol}^{-1}$ which is slightly higher than the threshold value of $40 \mathrm{kJmol}^{-1}$ associated with physical adsorption and far less than $100 \mathrm{kJmol}^{-1}$ associated with chemical adsorption signifying mixed-type adsorption nature with predominance of physisorption (Ituen et al, 2017). The negative value of entropy of adsorption shows that the destruction on the metal surface has been lowered as the result of decrease in disorderliness of the system (Ogunlaye et al, 2020).

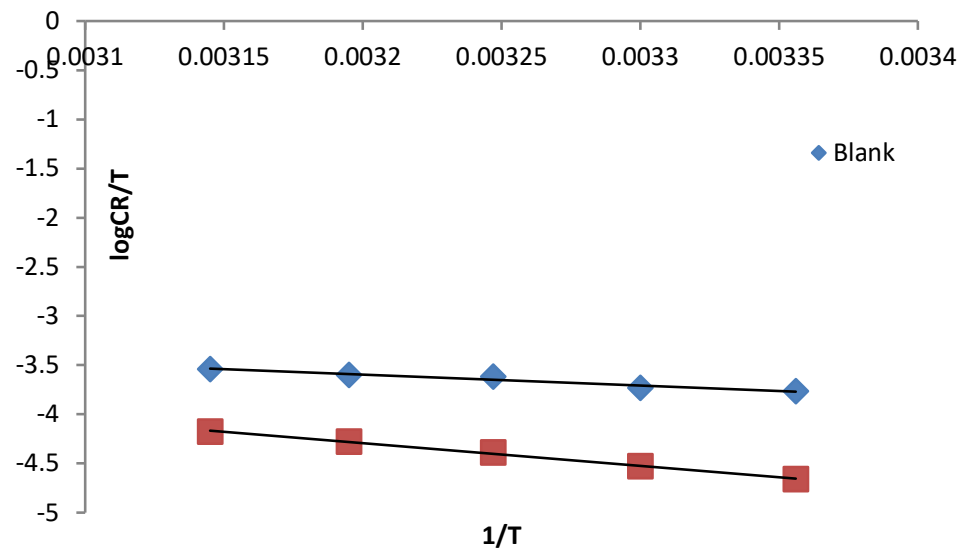

Fig. 4: Transition State Plot.

Table4: The Calculated Values of Activation Energy, Enthalpy and Entropy with and Without $0.1 \%$ Inhibitor

\begin{tabular}{llll}
\hline System & $\mathrm{E}_{\mathrm{a}}\left(\mathrm{kJmol}^{-1}\right)$ & $\Delta \mathrm{H}\left(\mathrm{kJmol}^{-1}\right)$ & $\Delta \mathrm{S}\left(\mathrm{kJmol}^{-1}\right)$ \\
\hline Blank & 24.00 & 21.30 & -0.21 \\
$\mathrm{HCl}+$ Inhibitor & 46.81 & 44.29 & -0.14 \\
\hline
\end{tabular}

The values of Gibb's free energy of adsorption $(\Delta G)$ were calculated using equation 9 and presented in table 5 .

$\Delta \mathrm{G}=-2.303 \mathrm{RT} \log (55.5 \mathrm{k})$

Where $\mathrm{R}$ is a gas constant, $\mathrm{T}$ is the absolute temperature, 55.5 is the water concentration and $\mathrm{k}$ is the adsorption equilibrium constant The negative sign of $(\Delta \mathrm{G})$ indicate spontaneous process of adsorption. The values $\Delta \mathrm{G}$ are less than the threshold value of $-40 \mathrm{kJmol}^{-1}$ required for chemisorption, suggesting that the adsorption of Acacia nilotica on the aluminium surface is through physisorption mechanism (Dominic and Monday, 2016).

Table 5: The Calculated Values of Gibb's Free Energy with $0.1 \%$ Inhibitor at Different Temperature

\begin{tabular}{lll}
\hline System & Temperature $(\mathrm{K})$ & $\Delta \mathrm{G}\left(\mathrm{kJmol}^{-1} \mathrm{k}^{-1}\right)$ \\
\hline & 298 & -09.55 \\
$1.0 \mathrm{M} \mathrm{HCl}$ & 303 & -09.61 \\
+ & 308 & -09.59 \\
$0.1 \%$ Inhibitor & 313 & -09.93 \\
\hline
\end{tabular}


FTIR: The FTIR spectra of Acacia nilotica indicates the presence of phenolic hydroxyl $(\mathrm{OH})$ and carbonyl group (CO). However, the corrosion products in the presence of Acacia nilotica shows that the stretching frequencies of the $\mathrm{OH}$ and $\mathrm{CO}$ shifted from $3360 \mathrm{~cm}^{-1}$ to $3339 \mathrm{~cm}^{-1}$ and 1639 to $1640 \mathrm{~cm}^{-1}$.The shifts in peaks of the FTIR spectra of the corrosion product in the presence of Acacia nilotica suggest that, there was interaction between the metal and some molecules of the inhibitor (Dominic and Monday, 2016).

(A)

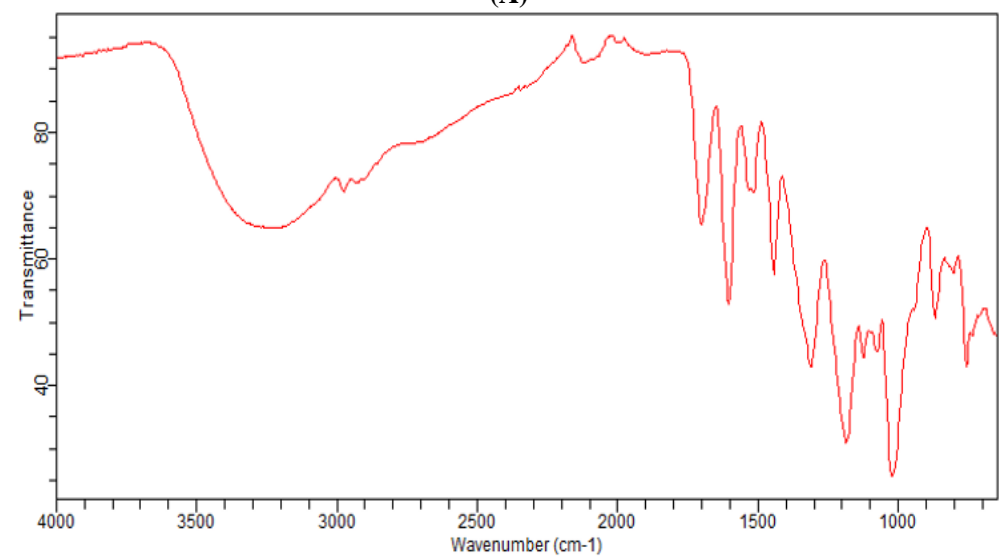

(B)

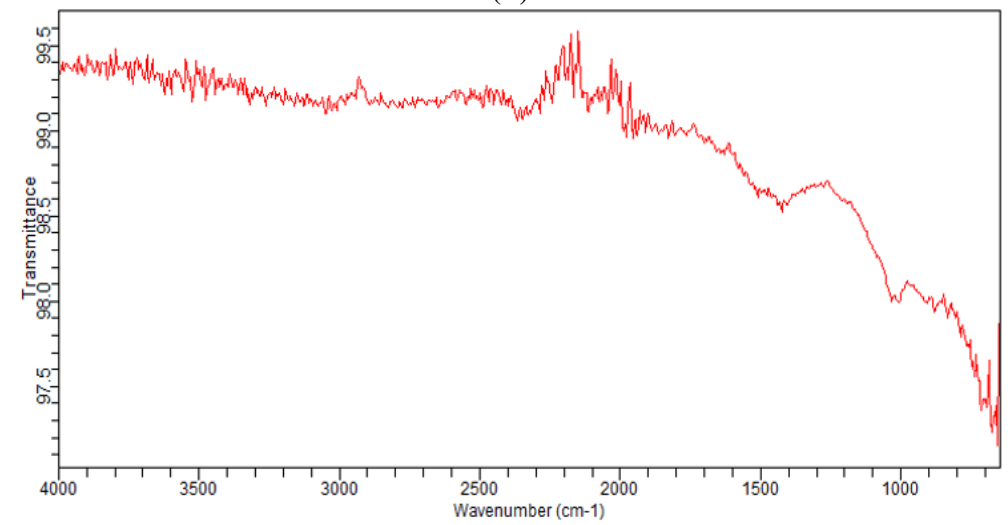

Fig. 5: FTIR Spectra for Acacia nilotica Ethanol Extract (A) and Corrosion Products in the Presence of Acacia nilotica (B).

\section{Conclusion}

The findings of this work showed that Acacia nilotica fruits ethanol extract is a good inhibitor for the corrosion of aluminium in $\mathrm{HCl}$ but inactive in $\mathrm{NaOH}$. The thermodynamic and kinetic data proposed that Acacia nilotica adsoption was spontaneous and exothermic process and followed physical adsorption process.

\section{References}

[1] Aytac, A. (2010). " $\mathrm{Cu}(\mathrm{II}), \mathrm{Co}(\mathrm{II})$ and $\mathrm{Ni}(\mathrm{II})$ complexes of $\mathrm{Br}$ and $-\mathrm{OCH}_{2} \mathrm{CH}_{2}$, Substituted Schiff Bases as Corrosion Inhibitors for Aluminium in Acidic Media", J. Matr. Sci., 45: 6812 - 6818. https://doi.org/10.1007/s10853-010-4779-7.

[2] Bouhlal, F., Labjar, N., Abdoun, F., Mazkour, A., Serghini-Idrissi, M., Lofti, E, and El Hajji, S. (2020). Electrochemical and Thermodynamic Investigationon Corrosion Inhibition of C38 Steel in 1M Hydrochloric Acid Using the Hydrochloric Extract of Used Coffee Grounds. Hindawi International Journal of Corrosion, 2020: 1- 14. https://doi.org/10.1155/2020/4045802.

[3] Dominic, O. O. and Monday, O. (2016). Optimization of the Inhibition of Efficiency of Mango Extract as Corrosion Inhibitor of Mild Steel in 1.0 $\mathrm{M} \mathrm{H}_{2} \mathrm{SO}_{4}$ Using Response Surface Methodology. Journal of Chemical Technology and Metallurgy, 51(3): 302-314.

[4] El-Etre, A.Y. (2007). Inhibition of Acid Corrosion of Carbon Steel Using Aqueous Extract of Olive Oil Leaves. Journal of Colloid and Interface Science, 314(2007): 578-583. https://doi.org/10.1016/j.jcis.2007.05.077.

[5] Fouda, A. S., Elmorsi, M. A. and Elmekkawy A. (2013). Eco-friendly Chalcones Derivatives as Corrosion Inhibitors for Carbon Steel in Hydrochloric Acid Solution. African Journal of Pure Applied Chemistry, 7(10): 1-13. https://doi.org/10.5897/AJPAC2013.0520.

[6] Hajar, H. M., Zulkifili, F., Mohd Sabr, M. G. and Wan Nik, W. B. (2016). Protection Against Corrosion of Aluminium Alloy in Marine Envirounment by Lawsonia inermis. Hindawi International Journal of Corrosion, 2016(1): 1-5. https://doi.org/10.1155/2016/4891803.

[7] Hamdy, A. and El-Gendy, N. S. (2012). Thermodynamic, Adsorption and Electrical Studies for Corrosion Inhibition of Carbon Steel by Henna Extract in Acid Medium. Egyptian Journal of Petroleum, 22(1): 17-25. https://doi.org/10.1016/j.ejpe.2012.06.002.

[8] Ibrahim, M.B., Sulaiman, Z., Usman, B. and Ibrahim, M.A. (2019). Effect of Henna Leaves on the Corrosion of Inhibition of Tin in Acid and Alkaline Media. World Journal of Applied Chemistry, 4(4): 45-51. https://doi.org/10.11648/j.wjac.20190404.11.

[9] Ituen, E., Akaranta, O. and James, A. (2017). Evaluation of Performance of Corrosion Inhibitors Using Adsorption Isotherm Models: An Overview. Chemical Science International Journal, 18(1): 1-34. https://doi.org/10.9734/CSJI/2017/28976. 
[10] Ituen, E.B. Udo, U.E., Odozi, N.W. and Dan, E.U. (2013). Adsorption and Kinetic Thermodynamic Characterization of Aluminum Corrosion Inhibition in Sulphuric Acid by Extract of Astonia boonei. IDSR Journal of Applied Chemistry, 3: 52 - 59. https://doi.org/10.9790/5736-0345259.

[11] Khan, G., Newaz, K.M.C., Basirun, W. J., Ali, H. B., Faraj, F. L. and Khan, G. M. (2015). Application of Natural Product Extracts as Green Corrosion Inhibitor for Metal and Alloys in Acid Pickling Processes- A Review. Int. J. Electrochem. Sci., 10(2015): 6120-6134.

[12] Mahalakshmi, K., Nithya, R. and Mithyananthi, M.J.T. (2016). Adsorption and Inhibitive Properties of Ethanol Extracts of Acacia nilotica as a Green Corrosion Inhibitor for Mild Steel in Acidic Media. ISSN: 0974 - 2115. Journal of Chemical and Pharmaceutical Sciences.

[13] Maibalangu, B.M., Ibrahim, M.B. and Akinlola, L.K. (2017). Inhibitory Effect of African Pumpkin (Mormordica balsamina Linn.) on Copper Corrosion in Acidic Media. J. Appl. Environ. Manage, 21(6): 1067-1071. https://doi.org/10.4314/jasem.v21i6.12.

[14] Nwaedozie, J.M. Akpan, E.J. and Olufemi, A.O. (2015). Inhibition and Adso-Kinetic Studies of Gmelina aborea Fruit Extract on Corrosion of Armour Steel Plate in Hydrochloric Acid. International Journal of Scientific and Engineering Research, 6(9): $701-717$.

[15] Obot, I.B., Obi - Egbedi, N.O. (2008). "Fluconazole as an Inhibitor for Aluminum Corrosion in 0.1.0 M HCl" Colloids surf: A Physicochem. Eng. Asp. 330: 207 - 212. https://doi.org/10.1016/j.colsurfa.2008.07.058.

[16] Ogunlaye, O. O., Arikoola, A. O., Eletta, O. A., Agbede, O. O., Osho, Y. A. and Morakinyo, A. F. (2020). Green Corrosion Inhibition and Adsorption Characteristics of Luffa cylindrical Leaf Extract on Mild Steel in Hydrochloric Acid Envirounment. Heliyon, 6(2020): 1-12. https://doi.org/10.1016/j.heliyon.2020.e03205.

[17] Okafor, P. C., Ikpi, M. I., Uwah, I. E., Ebenson, E. E., Ekpe, U.J. and Umoren, S. A.(2008). Inhibitor Action of Phyllathus amarus Extract on the Corrosion of Mild Steel in Acidic Media. Corrs. Sci., 50: 2310-2317. https://doi.org/10.1016/j.corsci.2008.05.009.

[18] Palou, R. M., Olivares - Xomelt, O. and Likhanova, N. V. (2014). Environmental Friendly Corrosion Inhibitors. INTECH.

[19] Rafeal, M. P., Octavio, O. and Natalya, V. L. (2014). Enviromentally friendly Corrosion Inhibitors. INTECH. 431-465. https://doi.org/10.5772/57252

[20] Sharma, S. K. (2012). Green Corrosion Chemistry and Engineering: Opportunity Challenges. Willey-VCH Verlag GmbH \&Co. KGaA. First Edition: $1-32$.

[21] Thompson, N. G., Yunovich, M. and Dunmire, D. (2007). Corrosion Rev. 25: 247-262. https://doi.org/10.1515/CORRREV.2007.25.3-4.247. 